УДК 331.4

ПРАВОВЫЕ ОСНОВЫ ПРИМЕНЕНИЯ

ИННОВАЦИОННЫХ ЭЛЕКТРОННЫХ СИСТЕМ МЕНЕДЖМЕНТА БЕЗОПАСНОСТИ ТРУДА

\title{
LEGAL BASIS FOR THE USE OF INNOVATIVE ELECTRONIC OCCUPATIONAL SAFETY MANAGEMENT SYSTEMS
}

$$
\text { Д.Ю. Захаров }
$$

Санкт-Петербургский государственный экономический университет,

г. Санкт-Петербург, Российская Федерация

$$
\text { Ю.И. Захарова }
$$

Межрайонная Инспекция Федеральной налоговой службы № 23, г. Санкт-Петербург, Российская Федерация

\section{К.В. Ремишевская}

Санкт-Петербургский горный университет, г. Санкт-Петербург, Российская Федерация

Denis Yu. Zakharov

Saint-Petersburg State University of Economics, Saint-Petersburg, Russian Federation

Yuliya I. Zakharova Inter-District Inspection of the Federal Tax Service №23, Saint-Petersburg, Russian Federation

$$
\text { Karina V. Remishevskaia }
$$

Saint-Petersburg Mining University, Saint-Petersburg, Russian Federation

$$
\text { e-mail: nashnex@bk.ru }
$$


Аннотация. Внедрение в производственную деятельность новых, инновационных и все более совершенных электронных систем управления является неотъемлемой частью повышения эффективности труда, снижения рисков, связанных с человеческим фактором. Основной сложностью в системе контроля обеспечения безопасности работ повышенной опасности являются согласования различных уровней. Актуальными являются проблемы ответственности и влияния человеческого фактора при исполнении законодательных нормативноправовых актов. По состоянию на 2014 год, согласно данным Минкомсвязи РФ, 95 \% всего программного обеспечения для нефтегазовой отрасли в России составляли импортные решения. Внедрение отечественных решений в области обеспечения производственной и промышленной безопасности считается одним из приоритетных направлений развития как с точки зрения поддержки отечественных производителей инновационной продукции, так и с точки зрения независимости российской промышленности от продукции иностранных поставщиков. Вместе с тем, существует ряд инновационных, технологичных решений, позволяющих повысить оперативность процессов управления безопасностью технологических процессов и производств, обеспечить беспрерывный административно-производственный контроль удаленных производственных объектов в режиме реального времени, что особенно актуально учитывая масштабы Российской Федерации и труднодоступность районов ведения производственно-хозяйственной деятельности в нефтегазовой отрасли. Однако службы, ответственные за безопасность опасных производственных объектов, не спешат автоматизировать процессы управления безопасностью труда и использовать уже разработанные отечественные продукты.

В статье на конкретном примере рассмотрены правовые основания применения электронных систем управления безопасностью труда, отсутствие которых до недавнего времени являлось главным аргументом 
сторонников консервативного, бюрократического подхода к менеджменту в области промышленной безопасности и охраны труда.

Ввод в действие Федеральных норм и правил в области промышленной безопасности «Правила безопасного ведения газоопасных, огневых и ремонтных работ» в новой редакции призван, в том числе, снять барьеры на пути применения современных технологий. В свою очередь, оно приводит к необходимости изменений в трудовом законодательстве, созданию новых регламентирующих нормативно-правовых актов.

Abstract. The introduction of new, innovative and increasingly advanced electronic control systems into production activities is an integral part of improving labor efficiency and reducing the risks associated with the human factor. The main difficulty in the control system of ensuring the safety of increased danger is the coordination of various levels. The problems of responsibility and the influence of the human factor in the execution of legislative regulations are actual. As of 2014, according to the Ministry of Communications and Mass Media of the Russian Federation, $95 \%$ of all software for the oil and gas industry in Russia were imported solutions. The introduction of domestic solutions in the field of operational security and industrial safety is considered one of the priority directions of development both in terms of supporting domestic producers of innovative products and in terms of independence of the Russian industry from products of foreign suppliers. At the same time, there are a number of innovative, technological solutions that make it possible to increase the efficiency of safety management processes of technological processes and production, to ensure continuous administrative and production control of remote production facilities in real time, which is especially important due to scale of Russian Federation and the inaccessibility of areas of production and economic activities in the oil and gas industry. However, the services responsible for hazardous production facilities safety are in no hurry to automate labor safety management processes and use developed domestic products. 
The article deals with the legal grounds for the use of electronic safety management systems, the absence of which until recently was the main argument of the supporters of a conservative, bureaucratic approach to management in the field of industrial safety and labor protection.

The introduction of Federal norms and rules in the field of industrial safety «Rules for the safe conduct of gas hazardous, fire and repair work» in the new edition is designed, including, to remove barriers to the use of modern technologies. In turn, it leads to the need for changes in labor legislation, the creation of new regulatory legal acts.

Ключевые слова: управление, безопасность, электронная подпись, правила, наряд-допуск

Key words: management, safety, electronic signature, rules, permit to work

\section{Введение}

Развитие современных технологий администрирования и управления, в том числе, процессами промышленной безопасности и охраны труда на опасных производственных объектах способно значительно ускорить циклы принятия решений и тем самым повысить эффективность производства.

Согласно аналитическим материалам наиболее востребованными в будущем будут технологические решения и программные продукты, которые позволят выполнять проверку систем обеспечения промышленной безопасности с любого устройства в любом месте и в любое время.

Из обзора программных продуктов, представленных на рынке, ранее экспертами выделялись общие для всех недостатки, такие как отсутствие наличия всех элементов системы производственного контроля [1]. Однако на рынке имеются программные продукты, способные решать широкий спектр задач в области промышленной безопасности и охраны труда. 
Одним из примеров внедрения такого продукта стало внедрение на опасных производственных объектах [2] крупной нефтегазовой компании России электронной системы обеспечения безопасности работ, включающей в себя процедуру оформления нарядов-допусков с использованием электронной цифровой подписи (ЭЦП) [3].

\section{Анализ}

Внедрение электронной системы обеспечения безопасности позволяет принимать оперативные решения по работам повышенной опасности на основе актуальных объективных данных, централизованно управлять всеми процессами администрирования, в том числе оформлением нарядовдопусков. Внедрение подобных систем требует перехода внедряющей компании на электронный документооборот. Большинство крупных предприятий успешно внедрили и используют системы электронного документооборота в административной части, однако внедрение электронного документооборота в производственную часть предприятия у многих вызывает значительные затруднения. Так, например, в области обеспечения безопасности опасных производственных объектов существует проблема законности авторизации и подтверждения согласований в электронном виде вследствие высокой степени ответственности согласующего. Эта проблема напрямую затрагивает область оформления электронных нарядов-допусков, использующих электронную цифровую подпись. При этом не делается различия по виду ЭЦП, используется электронный носитель или человек ставит подпись стилусом на специальном сенсорном экране. В это же время ЭЦП на цифровом носителе признается государством для совершения сделок, подписания договоров с государственными фондами и прочими организациями, подачи документов в суды различных уровней.

Применение в России электронной цифровой подписи регулируется Федеральным законом «Об электронной подписи» от 06.04.2011 N 63-Ф3 
[4]. Согласно тексту закона, электронная подпись - информация в электронной форме, которая присоединена к другой информации в электронной форме (подписываемой информации) или иным образом связана с такой информацией и которая используется для определения лица, подписывающего информацию. Федеральный закон регулирует отношения в области использования электронных подписей при совершении гражданско-правовых сделок, оказании государственных и муниципальных услуг, исполнении государственных и муниципальных функций, при совершении иных юридически значимых действий, в том числе в случаях, установленных другими федеральными законами. Но отдельно применение электронной цифровой подписи в документообороте обеспечения безопасности опасных производственных объектов законом не урегулировано. Как было указано, ввиду высокой степени ответственности за жизнь и здоровье рабочего персонала, которые несут в себе данные действия по согласованию ведения работ, предприятия отвечали отказом на предложения вводить электронные средства оформления нарядов-допусков.

Предлагались и разрабатывались дополнительные виды производственных инструкций, например инструктивная карта безопасных методов и приемов труда, которая обладает большей наглядностью, чем существующая документация, что дает возможность совершенствовать процесс обучения персонала, повышает качество проводимых инструктажей, а также снижать риск возникновения аварий, инцидентов, производственного травматизма [5]. Однако разработка подобной документации не упрощает систему контроля и не решает задач автоматизации процессов.

Разрабатываются и внедряются системы управления безопасностью труда на основе технологий видеонаблюдения [6]. Гибкость систем позволяет корректировать параметры (количество и месторасположение камер, количество мобильных устройств) в соответствии с требованиями 
организации-эксплуатанта опасного производственного объекта. Но данные системы не способны решить задачи упрощения документооборота.

\section{Существующие и предлагаемые решения}

Федеральной службой по экологическому, технологическому и атомному надзору были утверждены «Правила безопасного ведения газоопасных, огневых и ремонтных работ» [7]. Ключевыми являются изменения, касающиеся возможности применения электронных систем при организации работ повышенной опасности, а именно:

- пункт 2.1.11 «Допускается ведение журнала регистрации нарядовдопусков на проведение газоопасных работ в электронном виде»;

- пункт 2.2.5 «Возможность использования электронной подписи при согласовании нарядов-допусков на проведение газоопасных работ устанавливается внутренними документами эксплуатирующей организации в соответствии с требованиями Федерального закона от 6 апреля 2011 г. № 63-Ф3 «Об электронной подписи». Допускается оформление и регистрация наряда-допуска на проведение газоопасных работ в электронном виде».

Аналогичные изменения касаются организации огневых работ (пункт 3.2.12) и ремонтных работ (пункт 4.2.16). Кроме того, в этих пунктах установлены правила и условия хранения нарядов-допусков по огневым и ремонтным работам, а именно - пункт 4.2.16 «Должна быть исключена возможность несанкционированного изменения информации в нарядедопуске на проведение ремонтных работ, а также обеспечены условия хранения наряда-допуска на проведение ремонтных работ в течение одного года со дня его закрытия».

Также, в дополнение, необходимо развитие законодательства в области промышленной безопасности и охраны труда, направленное на: 
1) развитие использования в системе управления безопасностью труда систем связи и видеонаблюдения, в том числе использующих современные стандарты связи HSDPA+ и LTE. Данное решение способствовало бы расширению функционала применяемых инновационных систем мониторинга и административно-производственного контроля. Программные комплексы административно-производственного контроля при должном нормативно-правовом сопровождении позволили ли бы вовлекать персонал всех уровней в процесс поиска и идентификации потенциальных опасностей, выявлять отклонения в режиме реального времени, регистрировать их и, как следствие, предотвращать значительные сбои в работе и снижать травмоопасность производства $[8,9]$;

2) разработку отдельных требований по порядку извещения и расследования аварийных ситуаций и несчастных случаев на значительно удаленных производственных объектах и регламентацию использования в данном процессе программных продуктов.

\section{Вывод}

Ввод в действие новых правил открывает возможности юридически легитимных действий по внедрению электронных систем управления безопасностью труда различных уровней, решающих широкий спектр задач (рисунок 1).

Создается задел как для применения существующих, так и для разработки новых технологических решений, основанных на использовании электронной цифровой подписи.

Данные решения упрощают задачи управления безопасностью работ на удаленных производственных объектах. 


\section{ФУНКЦИОНАЛ ИННОВАЦИОНЫХ \\ ЭЛЕКТРОННЫХ СИСТЕМ \\ УПРАВЛЕНИЯ БЕЗОПАСНОСТЬЮ}

(2) Административно-

производственный контроль

Наряд-допуски

욜 Вовлеченность персонала

(10) Мониторинг в режиме реального времени

In Реагирование и расследование

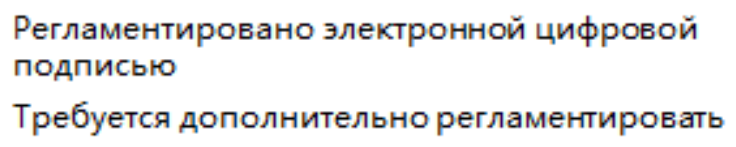

Рисунок 1. Функционал инновационных систем управления безопасностью труда

Тем не менее, применение юридически верифицированной электронной цифровой подписи не полностью решает проблему использования инновационных электронных систем управления безопасностью. Требуется проведение анализа нормативно-правовых актов с целью выявления и устранения их несовершенства в рассматриваемой области.

\section{Список используемых источников}

1. Кабирова Э.Р., Ахметова Д.Д., Солодовников А.В., Фатхутдинов Р.И. Обзор программных продуктов, позволяющих автоматизировать процедуры производственного контроля на опасных производственных объектах нефтегазодобывающих производств // Сетевое издание «Нефтегазовое дело». 2017. № 6. С. 147-164. 
2. Ф3 № 116 «О промышленной безопасности опасных производственных объектов». URL: http://www.consultant.ru/document/ cons_doc_LAW_15234 (дата обращения: 18.01.2019).

3. «Газпромнефть-Хантос» завершила пилот внедрения системы обеспечения безопасности работ. URL: http://www.tadviser.ru/ index.php/Проект\%3АГазпромнефть-Хантос_\%28Визитек\%3А_ИСОБР\%29 (дата обращения: 18.01.2019).

4. Ф3 № 63 «Об электронной подписи». URL: http://www.consultant.ru/document/cons_doc_LAW_112701 (дата обращения: 18.01.2019).

5. Климова И.В. Инструктивные карты безопасных методов и приемов труда для отдельных видов работ, проводимых в нефтешахте // Записки горного института. 2017. Т. 225. С. 354-359.

6. Захаров Д.Ю. Управление рисками аварийных ситуаций на основе совершенствования систем реагирования // Нефтяное хозяйство. 2013. № 10 (1081). C. 132-135.

7. Приказ № 485 Ростехнадзора от 20.11.2017. Об утверждении Федеральных норм и правил в области промышленной безопасности «Правила безопасного ведения газоопасных, огневых и ремонтных работ». URL: http://docs.cntd.ru/document/555931055 (дата обращения: 18.01.2019).

8. Захаров Д.Ю. Повышение качества административнопроизводственного контроля путём вовлечения персонала всех уровней в процесс поиска опасностей // Ресурсы Европейского Севера. Технологии и экономика освоения. 2016. № 4. С. 60-66.

9. Веселков В.Г. Информационная система мониторинга как инструмент повышения эффективности осуществления административнопроизводственного контроля состояния охраны труда и промышленной безопасности // Газовая промышленность. 2017. № 2. С. 30-38. 


\section{References}

1. Kabirova E.R., Akhmetova D.D., Solodovnikov A.V., Fatkhutdinov R.I. Obzor programmnykh produktov, pozvolyayushchikh avtomatizirovat' protsedury proizvodstvennogo kontrolya na opasnykh proizvodstvennykh ob"ektakh neftegazodobyvayushchikh proizvodstv [Overview of Software Products Allowing to Automate Procedures for Production Control at Hazardous Production Facilities of Oil and Gas Production Facilities]. Setevoe izdanie «Neftegazovoe delo» - Online Edition «Oil and Gas Business», 2017, No. 6, pp. 147-164. [in Russian].

2. FZ № 116 «O promyshlennoi bezopasnosti opasnykh proizvodstvennykh $o b "$ "ektov» [Federal Law «On Industrial Safety of Hazardous Production Facilities») Available at: http://www.consultant.ru/document/ cons_doc_LAW_15234/ (accessed 18.01.2019). [in Russian].

3. «Gazpromneft'-Khantos» zavershila pilot vnedreniya sistemy obespecheniya bezopasnosti rabot ["Gazpromneft-Khantos" Completed the Pilot Implementation of the System Security Works]. Available at: http://www.tadviser.ru/index.php/Проект\%3АГазпромнефть-Хантос_\%28Визитек\%3А_ИСОБР\%29 (accessed 18.01.2019). [in Russian].

4. FZ № 63 «Ob elektronnoi podpisi» [Federal Law «About Electronic Signatures»]. Available at: http://www.consultant.ru/document/ cons_doc_LAW_112701/(accessed 18.01.2019). [in Russian].

5. Klimova I.V. Instruktivnye karty bezopasnykh metodov i priemov truda dlya otdel'nykh vidov rabot, provodimykh v nefteshakhte [Instructional Maps of Safe Methods and Methods of Work for Certain Types of Work Carried out in the Oilfield]. Zapiski Gornogo instituta - Journal of Mining Institute, 2017, Vol. 225, pp. 354-359.

6. Zakharov D.Yu. Upravlenie riskami avariinykh situatsii na osnove sovershenstvovaniya sistem reagirovaniya [Emergency Risk Management Through Improved Response Systems]. Neftyanoe khozyaistvo - Oil Industry, 2013, No. 10 (1081), pp. 132-135. [in Russian]. 
7. Prikaz № 485 Rostekhnadzora ot 20.11.2017. Ob utverzhdenii Federal'nykh norm $i$ pravil $v$ oblasti promyshlennoi bezopasnosti «Pravila bezopasnogo vedeniya gazoopasnykh, ognevykh i remontnykh rabot» [Order No. 485. About the Approval of Federal Regulations and Rules in the Field of Industrial Safety «Rules of Safe Conducting Gas-Hazardous, Fire and Repair Works»]. Available at: http://docs.cntd.ru/document/555931055 (accessed 18.01.2019).

8. Zakharov D.Yu. Povyshenie kachestva administrativnoproizvodstvennogo kontrolya putem vovlecheniya personala vsekh urovnei $\mathrm{v}$ protsess poiska opasnostei [Improving the Quality of Administrative and Production Control by Involving Personnel at All Levels in the Search for Hazards]. Resursy Evropeiskogo Severa. Tekhnologii i ekonomika osvoeniya Resources the European North. Exploration Technologies and Economics, 2016, No. 4, pp. 60-66. [in Russian].

9. Veselkov V.G. Informatsionnaya sistema monitoringa kak instrument povysheniya effektivnosti osushchestvleniya administrativnoproizvodstvennogo kontrolya sostoyaniya okhrany truda i promyshlennoi bezopasnosti [Information Monitoring System as a Means to Increase the Efficiency of Administrative and Production Control over Health and Safety]. Gazovaya promyshlennost' - Gas Industry, 2017, No. 2, pp. 30-38. [in Russian].

\section{Сведения об авторах}

\section{About the authors}

Захаров Денис Юрьевич, кандидат технических наук, ведущий экономист, Санкт-Петербургский государственный экономический университет, г. Санкт-Петербург, Российская Федерация

Denis Yu. Zakharov, Candidate of Engineering Sciences, Leading Economist, Saint-Petersburg State University of Economics, Saint-Petersburg, Russian Federation

e-mail: nashnex@bk.ru 
Захарова Юлия Игоревна, специалист 1 разряда Межрайонной Инспекции Федеральной Налоговой службы № 23, г. Санкт-Петербург, Российская Федерация

Yuliya I. Zakharova, $1^{\text {st }}$ category Specialist of Inter-District Inspection of the Federal Tax Service No. 23, Saint-Petersburg, Russian Federation

e-mail: joyinly@gmail.com

Ремишевская Карина Викторовна, студент кафедры организации и управления, Санкт-Петербургский горный университет, г. СанктПетербург, Российская Федерация

Karina V. Remishevskaia, Student of Organization and Management Department, Saint-Petersburg Mining University, Saint-Petersburg, Russian Federation

e-mail: heyjude945@gmail.com 